\title{
O CONCEITO DE “SENTIDO” EM VYGOTSKY: CONSIDERAÇÕES EPISTEMOLÓGICAS E SUAS IMPLICAÇÕES PARA A INVESTIGAÇÃO PSICOLÓGICA*
}

\author{
João Paulo Pereira Barros \\ Luana Rêgo Colares de Paula \\ Jesus Garcia Pascual \\ Veriana de Fátima Rodrigues Colaço \\ Verônica Morais Ximenes \\ Universidade Federal do Ceará, Fortaleza, Brasil
}

\begin{abstract}
RESUMO: Este artigo objetiva resgatar o conceito de "sentido" como recurso analítico nas investigações psicológicas, a partir de deslocamentos e conexões construídas na história epistemológica das ideias de Lev Vygotsky. Para isso, apresentam-se interlocuções e rupturas desse autor com matrizes de pensamento e correntes psicológicas do início do século XX, o que fornece um panorama das possibilidades até então construídas para a compreensão do conceito de "sentido". Posteriormente, tematizam-se nuanças epistemológicas e metodológicas do tratamento dispensado por Vygotsky ao conceito em questão. Conclui-se que, nessa perspectiva, o "sentido" é concebido como acontecimento semântico particular constituído através de relações sociais, nas quais uma gama de signos é posta em jogo, o que permite a emergência de processos de singularização em uma trama interacional histórica e culturalmente constituída. Salientam-se, por fim, algumas implicações dessa concepção para as investigações psicológicas que abordam as práticas sociais e seus processos de significação.
\end{abstract}

PALAVRAS-CHAVE: sentido; teoria histórico-cultural; processos de singularização; processos de significação.

\section{THE CONCEPT OF “MEANING” IN VYGOTSKY: EPISTEMOLOGICAL APPRECIATIONS AND ITS IMPLICATIONS FOR THE PSYCHOLOGICAL RESEARCH.}

\begin{abstract}
This article has the objective of rescuing the concept of "meaning" as analytical resource in the psychological researches from displacements and connections constructed in the epistemological history of Lev Vygotsky's ideas. For this, interlocutions and ruptures of this author with thought matrices and psychological chains from the beginning of the 20th century are presented, supplying a panorama of the until then constructed possibilities for understanding the concept of "meaning". Later, epistemological and methodological tones of the treatment excused by Vygotsky to the concept in question are discussed. It is concluded that, in this perspective, "meaning" is conceived as consisting as particular semantic event through social relations in which a gamma of signs is brought to discussion, which allows the emergency of processes of singularization in a plot of interaction culturally and historically constituted. It is pointed out, finally, some implications of this conception for the psychological researches that approach social practices and its processes of meaning. KEYWORDS: meaning; historical-cultural theory; singularization processes; meaning processes.
\end{abstract}

\section{Introdução}

Os questionamentos sobre as formas pelas quais o ser humano constrói "sentidos" sobre sua existência têm sido feitos reiteradamente pelas diversas psicologias (Figueiredo, 2000), em que pesem as marcantes heterogeneidades teórico-metodológicas das incursões sobre o tema. Nessa multiplicidade, vale citar as abordagens da Fenomenologia, da Gestalt, do Comportamentalismo, da Psicanálise e da Psicologia Genética
(Bock, Furtado, \& Teixeira, 1999), bem como destacar, especialmente, as formulações de Lev Vygotsky ${ }^{1}$, autor que, entre 1924 e 1934, empreendeu esforços de investigação em torno dos processos psicológicos eminentemente humanos, dando destaque crescente ao papel dos signos nesses processos.

Segundo Van der Veer e Valsiner (2001), a sistematização dos principais elementos da Teoria HistóricoCultural se desenvolveu, sobretudo, entre os anos 1928 e 1931. Afirmam ainda que, naquele período, quatro 
grandes obras são representativas: $\underline{\mathrm{O} \text { Comportamento de }}$ animais e do homem - escrita em 1929-30; Estudos sobre a história do comportamento. Primata. Primitivo. Criança - publicada em 1930; Instrumento e signo - escrita em 1930 - e A história do desenvolvimento das funções psicológicas superiores - publicada em 1931, considerada o produto mais completo da teoria em questão.

No entanto, algumas obras que antecedem e outras que sucedem aquele período merecem ênfase por sua relevância na trajetória de formação do pensamento vygotskiano. Uma delas é o manuscrito intitulado $\underline{\mathrm{O}}$ significado histórico da crise da psicologia (Vigotski, 1927/1996), e a outra se denomina Pensamento e Linguagem (Vigotski, 1934/2001b), na qual o conceito de "sentido" surge como um ponto nodal.

Diante desse panorama, duas questões compõem uma problemática epistemologicamente importante. Para autores como Rey (2003, 2004), Smolka (2004), Góes e Cruz (2006), o conceito de "sentido" ainda tem pouca notoriedade no conjunto das produções balizadas no legado de Vygotsky, embora constitua um divisor de águas de sua obra. Logo, impõe-se o desafio de dar maior visibilidade a tal conceito, para entender não só de que maneira ele retroalimenta as bases das teorizações vygotskianas e redimensiona outros pontos que a precederam, mas também que possibilidades ele oferece às investigações psicológicas que enfocam os processos de significação.

Levando em conta tanto essa problemática, quanto a pertinência da temática da significação na seara psicológica, esse artigo objetiva resgatar o conceito de "sentido" como recurso analítico nas investigações psicológicas, a partir de deslocamentos e conexões construídas na história epistemológica das ideias vygotskianas.

Para isso, primeiramente, apresentam-se interlocuções e rupturas de Vygotsky com algumas das principais matrizes de pensamento e correntes psicológicas do início do século XX, o que fornece um panorama das possibilidades de compreensão do conceito de "sentido" dentro do quadro apresentado por Vygotsky, referente às psicologias de seu tempo, e de algumas condições para a emergência do conceito de "sentido" no escopo vygotskiano. Num segundo momento, tematizam-se nuanças epistemológicas e metodológicas do tratamento dispensado por Vygotsky ao conceito em questão, salientando suas implicações para a investigação psicológica.

\section{Deslocamentos em relação às psicologias do século XX è̀s suas possibilidades de estudo do conceito de "sentido"}

Para aclarar que condições foram criadas para a tematização sobre o conceito de "sentido" dentro das formulações vygotskianas, importa, de início, assinalar que a constituição dos principais apontamentos desse autor está relacionada às suas interlocuções com algumas matrizes de pensamento e correntes psicológicas em voga nas primeiras décadas do século XX. Desse modo, o Manuscrito intitulado $\underline{\mathrm{O} \text { Significado Histórico da Crise da Psicologia }}$ (Vigotski, 1927/1996) figura como um dos marcos principais da história epistemológica das ideias vygotskianas e como um prelúdio dos elementos que passaram a compor a Teoria Histórico-Cultural a partir de 1928.

Nesse manuscrito, Vygotsky (1927/1996) apresentou o estado em que se encontravam a psicologia e as formas de construção de conhecimentos sobre o psiquismo. Para tanto, sob um prisma metodológico, foram analisadas as possibilidades de surgimento e os direcionamentos das principais correntes daquele período, como a fisiologia de Pavlov, a reflexologia de Bekhterev, a reactologia de Kornilov, o behaviorismo watsoniano, a psicanálise, o personalismo e a Psicologia da Gestalt.

$\mathrm{O}$ ápice dessa análise radicou-se na tese histórica e metodológica de que a crise da psicologia se formulava com base em uma crescente ruptura entre duas psicologias, "uma psicologia científico-natural e a outra idealista" (Vigotski, 1927/1996, p. 338). Nesse cenário polarizado, marcado pela disputa entre diferentes pontos de partida epistemológicos e entre métodos de investigação de base naturalista e mentalista, os processos psicológicos ora eram tratados como processos biológicos ou mesmo físicos, ora como fenômenos transcendentais e metafísicos, respectivamente.

O primeiro grupo aspirava à explicação e previsão do comportamento humano. Para isso, seu percurso de investigação transitava do simples ao complexo, buscando, em cada fenômeno investigado, a identificação dos elementos mínimos que o compunham. Também, nesse método, deduzia-se uma regularidade geral para uma série de fenômenos a partir da observação de um representante típico desses fenômenos. Segundo Vygotsky (1927/1996, p. 338),

o método da psicologia explicativa é idêntico ao das ciências naturais, e seu postulado (que não existe nenhum fenômeno psíquico sem um fenômeno físico correspondente) a conduz à falência como ciência independente, seus problemas passando para as mãos da fisiologia.

Embora, no começo de seu trabalho, conforme indicam Van der Veer e Valsiner (2001), Vygotsky tenha sido influenciado pela noção de psiquismo como uma cadeia de reflexos, a qual entremeia livros como Psicologia da Arte (Vigotski, 1925/1998) e Psicologia Pedagógica (1926/2001a), sua crítica aos métodos de investigação reflexológicos pode ser encontrada desde sua participação no Segundo Congresso Neuropsicológico de Moscou, em 1924, marco da sua entrada na psicologia da capital soviética. Naquela ocasião, o autor já argumentava que os estudos desenvolvidos por 
Bekhterev e Pavlov, apesar de tratarem com êxito dos processos simples, não abordavam de fato os complexos processos eminentemente humanos, inclusive porque excluíam a possibilidade de que a consciência viesse a ser um objeto de estudo da psicologia.

No período de sistematização atinente à crise da psicologia, as ideias de Pavlov, bem como as primeiras versões do behaviorismo e a reflexologia Bekhtereviana, aparecem nas reflexões de Vygotsky como emblemas dessa psicologia alicerçada em uma matriz de pensamento atomicista e mecanicista, da qual esse autor se distanciará cada vez mais significativamente no percurso de construção de suas ideias. Para Figueiredo (2000, p. 67),

o atomismo na decomposição do fluxo comportamental e o mecanicismo na explicação de processos psicológicos estão historicamente associados à formação do conceito de reflexo. ... O comportamento complexo e contínuo deveria, portanto, ser analisado de forma a que se identificassem seus elementos - a sucessão de estímulos e respostas. ... A essa rigidez, Bechterev e Pavlov acrescentaram uma fonte de plasticidade, concebida ela mesma, porém, sob a forma de um mecanicismo rígido: o condicionamento por associação entre estímulos.

No entanto, cumpre assinalar que Vygotsky identificou algumas diferenças no bojo da psicologia científico-natural. Isso o fez aproximar-se mais de uma de suas correntes, a reactologia, principalmente a partir de sua entrada no Instituto de Psicologia Experimental de Moscou, em 1924, sob a direção de Kornilov, fato que se atesta nas produções de Vygotsky que antecedem a Teoria Histórico-Cultural. Os avanços da reactologia, para Vygotsky, justificam-se porque sua unidade de análise não era o reflexo, como na reflexologia, mas sim a "reação", pressupondo, dessa forma, uma mutualidade entre sujeito-objeto.

A despeito desse reconhecimento, a análise vygotskyana sobre a crise da psicologia operou questionamentos paradigmáticos também às bases da reactologia. As principais críticas, em primeiro lugar, incidiam no fato de que a explicação reactológica implicava uma similitude entre os comportamentos dos seres humanos e dos demais animais; em segundo lugar, enfocavam o fato de que Kornilov corroborava a retórica ideológicofilosófica que procedia a aplicação da crítica do materialismo dialético à psicologia, assim como sustentava o tradicional dualismo mente-corpo. Sobre este último ponto, afirma Vygotsky (1925/1982, citado por Van der Veer e Valsiner, 2001, p. 153), que “... não é possível estudar a psicologia em termos de reações, já que dentro das reações estão incorporados dois elementos [mente e corpo] funcionalmente dependentes que não podem ser reduzidos a uma unidade".

Em suma, o panorama da psicologia científiconatural apresentado por Vygotsky indicou que essa buscava se estabelecer como ciência sob os moldes de um método experimental. Uma vez que o interesse dessa psicologia estava nas unidades simples e nos processos psicológicos naturais passíveis de mensuração e observação, diluía-se a possibilidade de se conceber o conceito de "sentido" como criação e experiência subjetiva, pois, a partir desses referenciais, havia espaço tão-somente para associá-lo aos processos psicofisiológicos, na condição de experiência sensorial (Namura, 2004).

Por seu turno, a psicologia idealista também não satisfazia Vygotsky. Essa considerava a psicologia uma ciência da alma, partindo de dois pressupostos epistemológicos diametralmente opostos aos da psicologia naturalista, quais sejam, de que havia "uma diferença radical entre a natureza física e a existência psíquica" (Vigotski, 1927/1996, p. 377), e de que os processos propriamente humanos não poderiam ser estudados objetivamente. Por isso, tal psicologia lançava mão de um método mentalista que "... não tende à explicação, mas à descrição e compreensão" do comportamento (Vigotski, 1927/1996, p. 339).

Dentre as teorias que compunham este grupo, Vygotsky teve uma aproximação mais significativa com a Psicologia da Gestalt, ainda que sua visão sobre essa escola alemã tenha se transformado bastante entre 1924 e 1934. Para Van der Veer e Valsiner (2001), as considerações de Vygotsky sobre a Psicologia da Gestalt denotavam uma "dupla perspectiva", pois, ao mesmo tempo em que enfatizava sua importância e seus avanços, o autor russo explicitava os limites daquela escola para resolver a crise da psicologia.

Os dois primeiros vetores de entrelaçamento entre a Psicologia da Gestalt e as reflexões de Vygotsky foram a crítica ao "elementarismo", característico da psicologia científico-natural, e, sobretudo, a ideia de estrutura, a qual, em princípio, parecia superar o dualismo que, segundo a leitura vygotskiana, também pairava a psicologia naturalista. Figueiredo (2000, p. 157) frisa, de forma elucidativa, esses dois aspectos:

Os autores gestaltistas assumiram integralmente as críticas ao elementarismo, negando a realidade independente dos elementos ... e estendendo a ideia de uma estrutura organizadora a todos os níveis e a todas as áreas da experiência. ... O dado básico da psicologia da forma é a experiência imediata. Só que, ao contrário de Wundt, ao invés de dissecar esta experiência para identificar as suas unidades mínimas e, em seguida, reconstruir os fenômenos complexos, tratava-se, para os gestaltistas, antes de mais nada, de descrever e compreender os fenômenos que, espontaneamente, se ofereciam na experiência dos sujeitos e dos seus observadores.

Curiosamente, o próprio mote de aproximação entre Vygotsky e a Psicologia da Gestalt transformouse posteriormente em um propulsor para que diferenças 
fundamentais se estabelecessem entre ambos. Isso porque Vygotsky passou a sublinhar o risco de que a noção de Gestalt reduzisse todos os fenômenos à noção de estrutura. Segundo Van der Veer e Valsiner (2001, p. 179),

Entre as áreas de divergência de Vygotsky com a psicologia da gestalt estavam seu receio de que a psicologia da gestalt retornasse a explicações vitalistas e mecanicistas, à 'similaridade excessiva' de problemas dessa psicologia com a física contemporânea, à ausência da perspectiva social em questões psicológicas e à 'teoria intuitiva da mente'.

Com efeito, Vygotsky (1927/1996) advertia que era preciso reconstruir a noção de estrutura, atentando para a dimensão histórica de sua organização. Chegou, inclusive, a exclamar que a Psicologia da Gestalt havia recaído em um mecanicismo à proporção que não considerava o surgimento de novas estruturas, mas apenas o reestabelecimento do equilíbrio e "da boa forma" de estruturas já existentes.

Essas críticas de Vygotsky foram de suma importância para a consolidação da Teoria Histórico-Cultural, uma vez que nelas se encontravam alguns fundamentos de questões centrais dessa teoria, como a ênfase nas relações sociais e nos significados como constituintes do comportamento humano. É o que concluem Valsiner e Van der Veer (2001, p. 182):

assim, em 1932-3, Vygotsky havia começado a considerar a psicologia da gestalt uma 'psicologia naturalista' que, em seu núcleo teórico, não diferia da reflexologia, uma vez que reduzia significado à estrutura (Vygotsky, 1933g, 1982, p.159). A base para essa crítica foi a teoria histórico-cultural do próprio Vygotsky, que começara a enfatizar o papel dos significados na reorganização da estrutura dos fenômenos psicológicos.

Então, observa-se, pela angulação crítica vygotskiana, que a psicologia descritiva, ainda que diversa, intentava, sem exceção, definir um objeto próprio que a justificasse como ciência independente, versando sobre aspectos da vida humana que até então vinham sendo abordados, sobretudo, de forma racionalista e/ou idealista. Uma das ilustrações disso são as vias que esse grupo oferecia ao estudo do conceito de "sentido". Tomando como exemplo a Psicologia da Gestalt, embora desse visibilidade à percepção complexa ao invés da sensação e sugerisse uma ideia de sujeito, pode-se presumir que, nessa corrente, o "sentido" proviria de uma estrutura com organização centrada em si mesma.

Com base no que escreveu Vygotsky, nos idos de 1927, sobre os caminhos epistemológicos e metodológicos percorridos pelas psicologias, pode-se depreender que, ao criticar, por um lado, as correntes científiconaturais, o autor se afasta de perspectivas elementaristas e distancia-se da tendência a transpor mecanicamente à investigação do psiquismo tanto o método das ciências naturais, como os então exaltados conceitos filosóficos do marxismo. Ao mesmo tempo, suas assertivas sobre as correntes idealistas, por outro lado, mostram seu afastamento de uma matriz de pensamento estruturalista e de um método mentalista que inviabilizavam o estudo da consciência a partir de um método objetivo.

Uma questão central para esse debate é que, segundo Vygotsky, nenhuma das principais tendências vigentes no seu tempo lograva buscar uma explicação para o que há de especificamente humano no ser humano a partir da sua própria condição. Indício disso é o fato de que, em meio ao dualismo entre naturalistas e mentalistas, observamse também possibilidades duais quanto ao tratamento do conceito de "sentido", pois só era presumível associá-lo a uma esfera exterior, sendo capturável pelas sensações e percepções, ou ao âmbito de uma interioridade autossuficiente em relação à cultura (Namura, 2004).

Para se deslocar fundamentalmente dos caminhos então adotados por naturalistas e por mentalistas, Vygotsky busca subsídio metodológico no materialismo histórico-dialético de Marx e Engels. A seguinte citação deixa patente isso, além de mostrar uma forma qualitativamente nova de articulação do marxismo e da psicologia, se comparada às pretensões de Kornilov e outros psicólogos de menor expressão da época:

o que, sim, pode ser buscado nos mestres do marxismo não é a solução da questão, e nem mesmo uma hipótese de trabalho (porque essas são obtidas sobre a base da própria ciência), mas o método de construção. Não quero receber de lambuja, pescando aqui e ali algumas citações, o que é a psique, o que desejo é aprender na globalidade do método de Marx como se constrói a ciência, como enfocar a análise da psique (Vigotski, 1927/1996, p. 395).

Assim, Vygotsky aborda a constituição da condição humana através do que chama de "método inverso" ao da natureza, segundo o qual não se estuda tal condição a partir das funções psicológicas existentes nos demais animais, à luz de um viés meramente evolutivo e acumulativo, como era feito por Darwin, por Pavlov e pelos reflexologistas. Para Vygotsky (1927/1996, p. 207), a análise da gênese do ser humano continua tendo assento, porém desde que se tome como ponto de partida a atualidade e a particularidade humanas, pois "só podemos compreender cabalmente uma determinada etapa do processo de desenvolvimento - ou, inclusive, o próprio processo - se conhecemos o resultado ao qual se dirige esse desenvolvimento, a forma final que adota e a maneira como o faz".

Além da crítica ao dualismo das psicologias científico-natural e idealista, duas outras questões que se encontram claramente apontadas no Manuscrito de 1927, sob a inspiração da concepção materialista histórico-dialética, foram cruciais para a viabilidade epistemológica da inclusão do conceito de "sentido" nos últimos momentos da obra de Vygotsky. Uma delas 
é a afirmação da consciência como objeto de estudo da psicologia, tendo como princípio explicativo as relações sociais. A outra é a incorporação de um método genético pautado na historicidade dos processos psicológicos.

Esses três pontos levaram Vygotsky, já no final da década de 1920, a acentuar debates sobre a centralidade dos processos de significação na constituição social das funções psicológicas propriamente humanas, o que contribuiu, sobremaneira, para um salto qualitativo das possibilidades de estudo do psiquismo humano de um modo geral. Assim, na década de 1930, Vygotsky incluiu a relação entre pensamento e linguagem no estudo da consciência e, consequentemente, o conceito de "sentido" na trama dos processos de significação e da cultura.

\section{O conceito de "sentido" no pensamento de Vygotsky e suas implicações à investigação psicológica}

No texto "Pensamento e Palavra", Vygotsky (1934/2001b) afirma que a chave para o estudo da consciência humana está na relação entre pensamento e linguagem, fato que o leva a considerar a palavra como o microcosmo da consciência humana. As discussões que perpassam aquele texto se assentam na tese de que o vínculo entre tais processos se forja e se transforma no desenvolvimento histórico da consciência. Segundo o autor, a mútua constituição entre pensamento e linguagem baseia-se na premissa de que esta "não é um simples reflexo especular da estrutura do pensamento" (Vigotski, 1934/2001b, p.412), e de que o pensamento "não se exprime na palavra, mas nela se realiza" (Vigotski, 1934/2001b, p. 409).

A exemplo do que se observa no Manuscrito sobre a Crise da Psicologia, o autor faz um apanhado das produções existentes e identifica um impasse nas reflexões que se atinham à relação entre linguagem e pensamento, pois a maioria os considerava processos independentes e tentava estudar o pensamento discursivo mediante a decomposição de seus elementos. Diante disso, Vygotsky (1934/2001b) propõe-se a adotar um caminho metodológico distinto, elegendo, para tanto, o significado da palavra como unidade de análise da relação historicamente constituída entre pensamento e linguagem. Como o próprio Vygotsky (1934/2001b, p. 398) aponta, sua investigação avança em relação ao elementarismo porque o significado da palavra, por estar na interseção entre pensamento e linguagem, contém as propriedades do todo em função das quais se realiza a análise:

encontramos no significado da palavra essa unidade que reflete de forma mais simples a unidade do pensamento e da linguagem. ... Não podemos dizer que ele seja um fenômeno da linguagem ou um fenômeno do pensamento. A palavra desprovida de significado não é palavra, é um som vazio. Logo, o significado é um traço constitutivo indispensável da palavra. ... Deste modo, parece que temos todo o fundamento para considerá-la como um fenômeno do discurso. ... Do ponto de vista psicológico o significado da palavra não é senão uma generalização ou conceito. Generalização e significado da palavra são sinônimos. ... Consequentemente, estamos autorizados a considerar o significado da palavra como um fenômeno do pensamento.

Não obstante, conforme o próprio Vygotsky (1934/2001b), apesar de fundamental, essa não era a principal tese da investigação sobre esses processos. Para ele, o cerne e a inovação de seu estudo se radicavam na tese de que os significados das palavras se modificam e se desenvolvem na ontogênese.

A descoberta da inconstância e mutabilidade dos significados das palavras e do seu desenvolvimento é a descoberta principal e única capaz de tirar do impasse a teoria do pensamento e da linguagem. O significado da palavra é inconstante. Modifica-se no processo do desenvolvimento da criança. Modifica-se também sob diferentes modos de funcionamento do pensamento. É antes uma formação dinâmica que estática. (Vigotski, 1934/2001b, p.407, 408).

Com isso, o autor contraria, por um lado, a vertente associacionista do estudo do pensamento e da linguagem, para a qual o significado seria a associação entre a palavra e o objeto designado; e, por outro, a vertente estruturalista, para a qual a palavra e o objeto designado formariam uma estrutura igual a qualquer outra. Segundo Vygotsky (1934/2001b), em que pesem suas diferenças, tanto associacionistas quanto estruturalistas não consideravam a especificidade da palavra, tampouco o desenvolvimento dos seus significados. Por conseguinte, vê-se, nesse caso, à semelhança das considerações publicadas em 1927 sobre a crise da psicologia, que Vygotsky torna a balizar sua crítica às correntes psicológicas no princípio da historicidade dos processos eminentemente humanos, legado inextrincável do materialismo histórico-dialético.

É a partir dessa tese da dinamicidade do significado que o conceito de "sentido" aparece, em "Pensamento e Palavra", como fundamental para a investigação da relação pensamento-linguagem. Mais precisamente, Vygotsky (1934/2001b) introduz no debate a questão do "sentido" para reiterar as particularidades da linguagem interior, dirigida ao próprio sujeito, em relação à exterior, uma vez que, sob sua ótica, o predomínio dos sentidos sobre os significados da palavra na linguagem interior seria uma das maiores ilustrações disso.

Vygotsky (1934/2001b, p.465), inspirado na definição do psicólogo Francês Frederic Paulham sobre a relação entre "significado" e "sentido", conceitua este último da seguinte forma: 
o sentido de uma palavra é a soma de todos os fatos psicológicos que ela desperta em nossa consciência. Assim, o sentido é sempre uma formação dinâmica, fluida, complexa, que tem várias zonas de estabilidade variada. O significado é apenas uma dessas zonas do sentido que a palavra adquire no contexto de algum discurso e, ademais, uma zona mais estável, uniforme e exata.

A questão fundamental do debate ora proposto encontra-se, pois, no pressuposto de que essa definição proporciona que o "sentido" seja concebido como acontecimento semântico particular, constituído através de relações sociais, onde uma gama de signos é posta em jogo, o que permite a emergência de processos de singularização em uma trama interacional histórica e culturalmente situada. A partir disso, estabelecem-se novas possibilidades relativas à compreensão dos próprios processos de significação à luz da perspectiva histórico-cultural.

Um primeiro argumento em favor do redimensionamento dos processos de significação em decorrência do conceito de "sentido" é o de que este permite que a investigação psicológica passe a considerar, sobretudo, o caráter dinâmico, complexo e instável da significação, ao invés de se centrar tão-somente em suas zonas mais estáveis, os significados propriamente ditos, vistos como "apenas uma pedra no edifício dos sentidos" (Vigotski, 1934/2001b, p. 465). Como bem sublinha esse autor,

em contextos diferentes a palavra muda facilmente de sentido. O significado, ao contrário, é um ponto imóvel e imutável que permanece estável em todas as mudanças de sentido da palavra em diferentes contextos. Foi essa mudança de sentido que conseguimos estabelecer como fato fundamental na análise semântica da linguagem (Vigotski, 1934/2001b, p. 465).

Um segundo argumento na direção da ampliação das possibilidades de se entender o tema da significação diz respeito ao fato de que as nuanças da reflexão vygotskiana admitem inferir que o "sentido", assim como os signos, não estaria nem na mente, nem na natureza, nem em instâncias transcendentais aprioristicamente. O "sentido" se produziria nas práticas sociais, através da articulação dialética da história de constituição do mundo psicológico com a experiência atual do sujeito. Assim, abrem-se vias para que se admita a polissemia da linguagem e, consequentemente, para que se pense em múltiplas construções de sentidos.

Nessas produções, por sua vez, integram-se, por exemplo, dimensões cognitivas e afetivas, bem como processos coletivos e individuais. Destarte, o conceito de "sentido" se converte numa ferramenta relevante para se pôr em xeque dicotomias classicamente presentes no pensamento psicológico e reiteradamente criticadas por Vygotsky ao longo de sua produção intelectual, bem como para afirmar o psiquismo como um sistema dinâmico e integrado. Tal qual formula Rey (2004, p. 50),
Vygotsky já está visualizando o sistema dinâmico de sentidos como um novo nível de definição ontológica da psique, o que integra dentro de um mesmo sistema as diferentes instâncias que, em momentos anteriores, eram vistas separadamente. Vygotsky passa a representar a psique humana como um sistema complexo e integrado a partir de sua representação de 'sistema de signos'.

Decorre que, mediante a noção de "sentido" em questão, Vygotsky (1934/2001b), por um lado, renova e complexifica a ideia de que o psiquismo se forja socialmente, como apontam Góes e Cruz (2006). Por outro lado, suscita que a articulação entre relações sociais e processos psicológicos seja entendida como uma relação de recursividade e de constituição dialética, e não como uma relação de determinação causal do "social", visto unicamente como influência externa, sobre o indivíduo, tomado meramente como reflexo ou reação às injunções objetivas.

Diante disso, podem-se apresentar uma série de implicações para as investigações psicológicas que abordam as práticas sociais e seus processos de significação. A primeira delas é a de que as composições de sentidos, entendidas como formas singularizadas, porém socialmente constituídas, de experimentação de interações são necessariamente contextuais, como fica evidente nas palavras que seguem:

Esse enriquecimento das palavras que o sentido lhes confere a partir do contexto é a lei fundamental da dinâmica do significado das palavras. A palavra incorpora, absorve de todo o contexto com que está entrelaçada os conteúdos intelectuais e afetivos e começa a significar mais e menos do que contém o seu significado quando a tomamos isoladamente e fora do contexto: mais, porque o círculo dos seus significados se amplia, adquirindo adicionalmente toda uma variedade de zonas preenchidas por um novo conteúdo; menos, porque o significado abstrato da palavra se limita e se restringe àquilo que ela significa apenas em um determinado contexto. (Vigotski, 1934/2001b, pp. 465 - 466).

Eis aqui um segundo ponto fundamental, qual seja, de que o estudo das produções de sentidos, dentro de uma perspectiva histórico-cultural que vai de encontro à ideia de que tal produção se funda internamente, deve imbricar a palavra ao seu contexto de uso e às redes de interações que, de algum modo, viabilizam sua emergência. Logo, o que o sujeito diz no curso de uma investigação psicológica, por exemplo, não contém sentido em si mesmo, senão que consiste numa criação resultante tanto de suas interações face-a-face, quanto de suas relações com signos e outros sentidos que circulam nas tessituras sociais.

Um terceiro aspecto pertinente sugere que, em sendo os processos de significação configurados por meio de articulações cambiantes entre significados e 
sentidos, a investigação psicológica referente a isso lida, peremptoriamente, com um complexo jogo de forças entre zonas de semelhança e diferença com estabilidades distintas. Isso porque "o estudo das determinações da formação cultural do indivíduo deve admitir o jogo de forças unificadoras e dispersoras dos processos coletivos de significação" (Góes e Cruz, 2006, p. 43).

Um quarto ponto importante de ser frisado é o de que, por um lado, o "sentido" possui um caráter plurideterminado e ilimitado (Vigotski, 1934/2001b), o que incorre em estudos inescapavelmente contingenciais. Por outro lado, segundo o próprio Vygotsky, o fato de o "sentido" ter múltiplas zonas que variam em estabilidade faz com que sua formação não se dê aleatoriamente. Esse paradoxo aparece de forma elucidativa nas palavras de Smolka (2004, p. 12)

Os sentidos podem ser sempre vários, mas dadas certas condições de produção, não podem ser quaisquer uns. Eles vão se produzindo nos entremeios, nas articulações das múltiplas sensibilidades, sensações, emoções e sentimentos dos sujeitos que se constituem como tais nas interações; vão se produzindo no jogo das condições, das experiências, das posições, das posturas e decisões desses sujeitos; vão se produzindo numa certa lógica de produção, coletivamente orientada, a partir de múltiplos sentidos já estabilizados, mas de outros que também vão se tornando possíveis.

Duas outras implicações que se pode pensar é a de que a investigação psicológica se torna mais profícua na medida em que abandona a busca de "descobrir" sentidos acabados supostamente guardados no pensamento do sujeito e prontos para serem exteriorizados pela linguagem. Em contraponto a esse viés, as próprias interações fomentadas no curso da investigação psicológica envolvem negociações e composições de sentidos tanto por parte do pesquisador quanto do sujeito pesquisado. Isso porque, conforme salienta Smolka (2004, p. 11)

Não há sentido pré-definido, não há teleologia. Há múltiplas determinações que vão produzindo sentidos também múltiplos... A produção é inescapavelmente conjunta, a resultante nem sempre controlada... A significação, enquanto produção de signos e sentidos, é (resultante de) um trabalho coletivo em aberto, que implica ao mesmo tempo, acordo mútuo, estabilização, e diferença (interin-compreensão constitutiva...). Há sempre algo possível/ passível de ser comum, e há sempre heterogeneidade.

Em acréscimo, se, para Vygotsky (1934/2001b, p. 412), "a linguagem não serve como expressão de um pensamento pronto", posto que o constitui e modifica a sua estrutura, então, à luz da perspectiva históricocultural, não se pode considerar a existência de um "sentido puro" a ser apenas exteriorizado no contato do pesquisador e do sujeito pesquisado. Ao contrário, a partir do pensamento vygotskyano, pode-se afirmar que a linguagem em exercício numa conversação entre entrevistado-entrevistador, sobretudo, viabiliza a construção de sentidos sobre o(s) tema(s) da investigação.

Advém dessa linha analítica um sétimo aspecto sobremaneira relevante, por oportunizar um deslocamento claro na investigação dos processos de significação no bojo das práticas sociais. De acordo com esse aspecto, mais importante do que se fixar nos conteúdos da fala do(s) sujeito(s) pesquisado(s), torna-se fundamental à investigação se debruçar sobre "as condições de emergência e os modos de elaboração, funcionamento e sustentação da significação, sobre a possibilidade mesmo da produção de sentidos" (Smolka, 2004, p. 9).

Dentre essas condições, vale destacar um primeiro conjunto configurado, por exemplo, pelo contexto dos sujeitos pesquisados e pelas nuanças afetivo-volitivas que perpassam a construção do seu pensamento. Outrossim, como assevera Vygotsky (1934/2001b, p. 481), "para entender o discurso do outro, nunca é necessário entender apenas umas palavras; precisamos entender o seu pensamento. Mas é incompleta a compreensão do pensamento do interlocutor sem a compreensão do motivo que o levou a emiti-lo". Um outro conjunto de condições se constitui, por exemplo, pela conjuntura da pesquisa e pelas linhas teórico-metodológicas escolhidas pelo pesquisador.

\section{Considerações Finais}

A emergência do conceito de "sentido" na história epistemológica das ideias vygotskianas se deve aos deslocamentos feitos por Vygotsky em relação às psicologias do início do século XX e ao seu esforço sistemático em explicar a especificidade da condição humana, enfatizando, para tanto, a historicidade e o caráter semioticamente mediado dos processos psicológicos eminentemente humanos. Desse modo, no bojo do debate sobre a consciência, especificamente sobre as relações de mutualidade entre pensamento e linguagem, o conceito de "sentido", entendido como acontecimento semântico singular produzido nas relações do sujeito com signos que circulam nos contextos onde se insere, serve como recurso analítico para a superação de cisões e dualismos interno-externo, social-individual, cogniçãoemoção, mente-corpo, que marcavam as psicologias naturalista e idealista analisadas por Vygotsky em meados dos anos 20, bem como para afirmar que a formação social do ser humano é marcada por constantes transformações qualitativas e por processos de criação.

No que concerne à implicação desse conceito à investigação psicológica, pode-se inferir que ele contribui, sobremaneira, para o alargamento das possibilidades de estudos das interações sociais e dos processos de significação nelas inscritos. Isso porque abre vias para que se leve em conta não só recorrências e regularidades das in- 
terações e dos contextos pesquisados, mas também seus dinamismos, emergências e heterogeneizações, tendo em vista que, na composição de sentidos, articulam-se dialeticamente zonas de estabilidade e instabilidade.

Ao lançar mão do conceito de "sentido" nos estudos dos processos de significação, põem-se em xeque as pretensões de esgotar a complexidade do contexto investigado. Destarte, tal ferramenta analítica instiga posturas que vão de encontro às pretensões de encontrar sentidos "ocultos", seja em um sujeito "emsi-mesmado", seja em um contexto entendido como totalidade homogênea harmonicamente organizada que contém dados intrínsecos a serem "coletados". Fomenta, portanto, a que se entenda a investigação psicológica como negociação e composição de sentidos a partir de interações deflagradas em seu curso, nas quais não só a pessoa do pesquisador entra em jogo, como também suas interlocuções com suas teóricas de referência.

\section{Notas}

* Agradecimentos: à Coordenação de Aperfeiçoamento de Pessoal de Nível Superior (CAPES) e à Fundação Cearense de Apoio ao Desenvolvimento Científico e Tecnológico (FUNCAP).

1 Ao longo do texto, é usada a grafia do nome do autor "Vygotsky"; no entanto, de acordo com as fontes bibliográficas, são assinaladas demais grafias nas citações e referências.

\section{Referências Bibliográficas}

Bock, A. M. B., Furtado, O., \& Teixeira, M. L. T. (1999). Psicologias: uma introdução ao estudo da Psicologia (12 $2^{\mathrm{a}} \mathrm{ed}$.). São Paulo: Saraiva.

Figueiredo, L. C. M. (2000). Matrizes do pensamento psicológico ( $8^{\mathrm{a}}$ ed.). Petrópolis, RJ: Vozes.

Góes, M. C. R. \& Cruz, M. N. (2006). Sentido, significado e conceito: notas sobre as contribuições de Lev Vigotski. ProPosições, 17, 31-45.

Namura, M. R. (2004). Por que Vygotski se centra no sentido: uma breve incursão pela história do sentido na psicologia. Psicologia Educacional, 19, 91-117.

Rey, F. L. G. (2003). Sujeito e subjetividade. São Paulo: Pioneira Thomson Learning.

Rey, F. L. G. (2004). O social na psicologia e a psicologia social: a emergência do sujeito. Petrópolis, RJ: Vozes.

Smolka, A. L. B. (2004). Sobre significação e sentido: uma contribuição à proposta de rede de significações. In M. C. Rossetti-Ferreira, K. S. Amorim, A. P. S. Silva, \& A. M. A. Carvalho (Orgs.), Rede de significações e o estudo do desenvolvimento humano (Vol. 1, pp. 35-49). Porto Alegre: Artes Médicas.

Van Der Veer, R. \& Valsiner, J. (2001). Vygotsky: uma sintese. São Paulo: Loyola.

Vigotski, L. S. (1996). O significado histórico da crise da psicologia. In L. S. Vigotski. Teoria e método em psicologia. São Paulo: Martins Fontes. (Original publicado em 1927).

Vigotski, L. S. (1998). Psicologia da arte. São Paulo: Martins Fontes. (Original publicado em 1925).
Vygotski, L. S. (2000). La historia del desarrollo de las funciones psicologicas superiores. Obras escogidas: problemas del desarrollo de la psique (Tomo III). Madrid: Visor. (Original publicado em 1931).

Vigotski, L. S. (2001a). Psicologia pedagógica. São Paulo: Martins Fontes. (Original publicado em 1926).

Vigotski, L. S. (2001b). Pensamento e palavra. In L. S. Vigotski. A construção do Pensamento e da Linguagem. São Paulo: Martins Fontes. (Original publicado em 1934).

Vygotsky, L. S. \& Luria, A. (1996). Estudos sobre a história do comportamento: primata, homem primitivo e criança. Porto Alegre: Artes Médicas. (Original publicado em 1930).

Vygotski, L. S., \& Luria, A. (2007). El instrumento y el signo en el desarrollo del niño. San Sebastián de los Reyes Madrid: Fundación Infancia y Aprendizaje. (Original publicado em 1930).

João Paulo Pereira Barros é mestrando em Psicologia (UFC). Bolsista da Coordenação de Aperfeiçoamento de Pessoal de Nível Superior (CAPES). Endereço para Correspondência: Rua Maria Clara, 855, Bairro Jardim Guanabara. Fortaleza-CE. CEP: 60345-290. E-mail: jppbarros@yahoo.com.br

Luana Rêgo Colares de Paula é mestranda em Psicologia (UFC). Bolsista da Fundação Cearense de Apoio ao Desenvolvimento Científico e Tecnológico (FUNCAP). Email: luacolares@yahoo.com.br

Jesus Garcia Pascual é Professor Adjunto do Departamento de Psicologia da Universidade Federal do Ceará (UFC), Doutor em Educação (UFC), Docente do Mestrado em Psicologia da UFC. Email: garciapascual2001@yahoo.com.br

Veriana de Fátima Rodrigues Colaço é Professora Adjunta do Departamento de Psicologia da Universidade Federal do Ceará (UFC), Doutora em Educação (UFRGS), Pósdoutora em Psicologia (Universidade de Barcelona), Docente do Mestrado em Psicologia da UFC. Email: verianac@uol.com.br

Verônica Morais Ximenes é Professora Adjunta do Departamento de Psicologia da Universidade Federal do Ceará (UFC), Doutora em Psicologia (Universidade de Barcelona), Docente do Mestrado em Psicologia da UFC e Coordenadora do Núcleo de Psicologia Comunitária (NUCOM). Email: vemorais@yahoo.com.br

O conceito de "sentido" em Vygotsky: considerações epistemológicas e suas implicações para a investigação psicológica

João Paulo Pereira Barros, Luana Rêgo Colares de Paula, Jesus Garcia Pascual, Veriana de Fátima Rodrigues Colaço e Verônica Morais Ximenes

Recebido: 23/09/2008

Aceito: 13/03/2009 